\title{
Characterization of Salmonella spp. Isolates from Swine: Virulence and Antimicrobial Resistance
}

\author{
Hai Nguyen Thi ${ }^{1,+}{ }^{\text {, Thi-Thanh-Thao Pham }}{ }^{2,+}{ }^{\mathbb{C}}$, Barbara Turchi ${ }^{3}$, Filippo Fratini ${ }^{3}{ }^{\mathbb{D}}$, \\ Valentina Virginia Ebani ${ }^{3}$, Domenico Cerri ${ }^{3}$ and Fabrizio Bertelloni ${ }^{3, * \text { (D) }}$ \\ 1 Department of Animal Science, Hong Duc University, Thanh Hoa City 40000, Vietnam; nlhaitd@gmail.com \\ 2 Biology Faculty, Dalat University, 01 Phu Dong Thien Vuong, Da Lat, Lam Dong 66000, Vietnam; \\ thaoptt@dlu.edu.vn \\ 3 Department of Veterinary Science, University of Pisa, Viale delle Piagge 2, 56124 Pisa, Italy; \\ barbara.turchi@unipi.it (B.T.); filippo.fratini@unipi.it (F.F.); valentina.virginia.ebani@unipi.it (V.V.E.); \\ domenico.cerri@unipi.it (D.C.) \\ * Correspondence: fabrizio.bertelloni@unipi.it \\ + These authors contributed equally to the study.
}

Received: 11 November 2020; Accepted: 15 December 2020; Published: 17 December 2020

Simple Summary: Salmonella is a pathogenic bacterium able to infect both humans and animals. It is diffused worldwide and, generally, animals are a source of infection for humans. Among domestic animals, swine represents an important reservoir and a frequent source of human infection, especially in some countries like Italy. To acquire information on Salmonella, in particular about epidemiology, but also virulence, pathogenesis and antimicrobial resistance, is the basis for a cohesive control program. This manuscript describes an investigation conducted on Salmonella isolates from swine, where two important characteristics were evaluated: the pathogenicity and the antimicrobial resistance. A great variability was observed among investigated strains. Salmonella serovar Typhimurium was confirmed as one of the most virulent serovars; indeed, most isolates belonging to this serovar presented many of the searched virulence factors. A high level of antimicrobial resistance was observed for some compounds (sulfonamide, tetracycline, streptomycin and ampicillin), but not for the so-called "last line antibiotics", such as, for example, ciprofloxacin. The constant monitoring on circulating strains in reservoir animals is important to acquire information and set up adequate prophylaxis measures.

Abstract: Salmonella is one of the most important zoonotic pathogens worldwide. Swine represent typical reservoirs of this bacterium and a frequent source of human infection. Some intrinsic traits make some serovars or strains more virulent than others. Twenty-nine Salmonella spp. isolated from pigs belonging to 16 different serovars were analyzed for gastric acid environment resistance, presence of virulence genes $(m g t C, \operatorname{rhuM}, \operatorname{pip} B, \operatorname{sop} B, \operatorname{spv} R B C, \operatorname{gip} A$, sodCI, sopE), antimicrobial resistance and presence of antimicrobial resistance genes $\left(\right.$ bla $_{T E M}$, bla $a_{P S E-1}$, aadA1, aadA2, aphA1-lab, strA-strB, tet $A$, tet $B$, tet $C$, tet $G$, sul1, sul2, sul3). A percentage of $44.83 \%$ of strains showed constitutive and inducible gastric acid resistance, whereas $37.93 \%$ of strains became resistant only after induction. The genes sopB, pipB and $m g t C$ were the most often detected, with $79.31 \%, 48.28 \%$ and $37.93 \%$ of positive strains, respectively. Salmonella virulence plasmid genes were detected in a S. enterica sup. houtenae ser. $40: z_{4}, z_{23}:$-strain. Fifteen different virulence profiles were identified: one isolate (ser. Typhimurium) was positive for 6 genes, and 6 isolates ( 3 ser. Typhimurium, 2 ser. Typhimurium monophasic variant and 1 ser. Choleraesuis) scored positive for 5 genes. None of the isolates resulted resistant to cefotaxime and ciprofloxacin, while all isolates were susceptible to ceftazidime, colistin and gentamycin. Many strains were resistant to sulfonamide (75.86\%), tetracycline $(51.72 \%)$, streptomycin $(48.28 \%)$ and ampicillin $(31.03 \%)$. Twenty different resisto-types were identified. Six strains (4 ser. Typhimurium, 1 ser. Derby and 1 ser. Typhimurium monophasic variant) showed 
the ASSuT profile. Most detected resistance genes sul2 (34.48\%), tet A (27.58\%) and $\operatorname{str} A-\operatorname{str} B(27.58 \%)$. Great variability was observed in analyzed strains. S. ser. Typhimurium was confirmed as one of the most virulent serovars. This study underlines that swine could be a reservoir and source of pathogenic Salmonella strains.

Keywords: Salmonella; swine; gastric acid resistance; virulence genes; antimicrobial resistance

\section{Introduction}

Salmonellosis represents one of the most important zoonosis worldwide, and in 2018 in Europe, Salmonella enterica sub enterica was the second most common zoonosis agent [1]. In the epidemiology of this bacterium, food acts as the main source of infection and animals as asymptomatic carriers. Many domestic animals could be reservoirs of salmonellae and, in particular, swine are the animals most often infected by this bacterium [2].

To establish infection, salmonellae must exceed the stomach, where the gastric environment represents the first barrier encountered by enteric bacteria. Salmonellae possess the ability to survive the gastric acidity. In particular, for Salmonella serovar Typhimurium, two distinct mechanisms to survive low $\mathrm{pH}$ were identified: a constitutive/intrinsic acid resistance and an inducible acid resistance, which is activated in acid-shocked cells at $\mathrm{pH} 4.5$ [3]. At the intestinal level, in appropriate conditions, salmonellae could colonize and invade gut epithelium [4]. Almost all Salmonella possess the Salmonella Pathogenicity Island 1 (SPI1), a genetic element on the chromosome that contains virulence genes, encoding for factors involved in epithelial cells' invasion [5]. Presence of other SPI or single virulence genes could represent an advantage for bacteria to establish the infection. Salmonella Pathogenicity Island 5 (SPI5) encodes for effector proteins, in particular SopB, involved in triggering fluid secretion [6]. The genes sopE and gipA, transferred by phages, help Salmonella to invade host cells and to grow and survive in the Peyer's patches, respectively $[7,8]$. Systemic disease can occur in some cases. Salmonella Pathogenicity Island 2 (SPI2) is another well-conserved chromosomic element, it allows Salmonella to survive inside macrophage and it facilitates spreading through the host body [5]. Other mobile elements could facilitate this event: Salmonella Pathogenicity Island 3 (SPI3) and SPI5 encode factors that modify the macrophage environment; the spv genes, located on a virulence plasmid, are present in the majority of strains associated with extra-intestinal infections in humans and animals [9]; lastly, sodCI is a phage-associated gene that protects Salmonella against oxidative burst [10].

Antimicrobial resistance is not only a great problem of public health, but it could represent an advantage in Salmonella pathogenesis [11]. In recent years, a high percentage of antimicrobial-resistant salmonellae was frequently observed in Europe; in particular, resistance was observed for tetracycline, sulfonamides/sulfamethoxazole and ampicillin. Moreover, an increasing number of multidrug-resistant isolates were recovered [12,13]. In particular, ASSuT profile (ampicillin, streptomycin, sulfonamides, tetracycline) and ACSSuT profile (chloramphenicol, streptomycin, sulfonamides, tetracycline) represent two multidrug resistance profiles typically associated to more pathogenic strains [14]. Antimicrobial resistance genes, in particular the ones related to these specific profiles, could be present on mobile elements like plasmids and integrons. In particular, numerous antimicrobial resistance cassettes (ARC), harboring different combination of antimicrobial resistance genes, were identified in Salmonella integrons [15].

This work aims to characterize Salmonella spp. isolates from pig for some of their virulence traits. In particular, the strains have been evaluated for: (I) the ability to survive the gastric acid environment with and without low $\mathrm{pH}$ induction, (II) the presence of some virulence genes: $m g t C$ and $r h u M$ located on SPI3, pipB and $s o p B$ located on SPI5, spvR, spvC and $s p v B$ located on the Salmonella virulence plasmid, $\operatorname{gip} A$, sodCI and sopE located on prophage and (III) the resistance to 22 antimicrobials. 


\section{Materials and Methods}

\subsection{Samples, Bacterial Isolation and Characterization}

From January to December 2016, 1480 samples were collected from healthy pigs. In particular, 696 were fecal samples collected from swine of different farms via transrectal swab at slaughterhouse, immediately after jugulation, whereas 784 were organ samples (gut, spleen, liver and mesenteric lymph node) collected at slaughterhouse from 196 animals. All animals are Large withe swine, coming from intensive or semi-extensive farms located in Tuscany, Central Italy. All animals were adult, finishing pigs, regularly slaughtered, and no symptoms or lesions were recorded by official veterinarians during ante- and post-mortem examination, respectively.

Samples were kept at $4{ }^{\circ} \mathrm{C}$, transported within $4 \mathrm{~h}$ to the Bacteriology Laboratory of the Department of Veterinary Science, University of Pisa, and immediately analyzed. Salmonella spp. isolation was carried out as previously described [16]. All isolates were serotyped by the "Istituto Zooprofilattico Sperimentale Lazio e Toscana, sezione di Roma". Salmonella isolates belonging to the same serovars were analyzed with Pulsed Field Gel Electrophoresis (PFGE), as described by other authors [17]. Only one strain for each pulsotype was selected to avoid redundancy results in the subsequent investigations. Nine Salmonella strains, belonging to different serovars and pulsotypes, previously isolated from pigs, were also included in the study (1 S. ser. Derby, 1 S. ser. Mbandaka, 3 S. ser. Typhimurium, $1 S$. ser. Give, $1 S$. ser. Livingstone, $1 S$. ser. Infantis and $1 S$. ser. Choleraesuis).

\subsection{Resistance to Gastric Acid Environment}

To evaluate constitutive and inducible gastric acid resistance, the procedure described by Xia et al. [18] was employed without modifications. The fixed value to consider a strain resistant was $1 \%$ of survived cells.

\subsection{Presence of Virulence Genes}

DNA extraction was performed with the DNeasy Blood and Tissue Kit (Qiagen, GmbH, Hilden, Germany) from overnight bacterial cultures. Presence of the following genes was evaluated using primers and protocols reported by other authors: $m g t C, \operatorname{rhu} M, \operatorname{pip} B, \operatorname{sop} B, \operatorname{spv} R, \operatorname{spv} C, \operatorname{spv} B, \operatorname{gip} A, \operatorname{sod} C I$ and sopE [19-23].

\subsection{Antimicrobial Resistance}

Susceptibility to antimicrobials was evaluated with the disc diffusion test on Mueller Hinton Agar (Oxoid, Ltd., Basingstoke, UK), as described in the Clinical and Laboratory Standards Institute (CLSI) manual [24]. The following antibiotics were employed (Oxoid): amoxicillin-clavulanic acid $(\mathrm{AMC} ; 30 \mu \mathrm{g})$, ampicillin (AMP; $10 \mu \mathrm{g})$, amikacin (AK; $30 \mu \mathrm{g})$, cephalothin (KF; $30 \mu \mathrm{g})$, cefotaxime $(\mathrm{CTX} ; 30 \mu \mathrm{g})$, ceftazidime (CAZ; $30 \mu \mathrm{g})$, chloramphenicol (C; $30 \mu \mathrm{g})$, ciprofloxacin (CIP; $5 \mu \mathrm{g})$, colistin (CT; $10 \mu \mathrm{g}$ ), enrofloxacin (ENR; $5 \mu \mathrm{g})$, florphenicol (FFC; $30 \mu \mathrm{g})$, gentamycin (CN; $10 \mu \mathrm{g})$, kanamycin (K; $30 \mu \mathrm{g})$, nalidixic acid (NA; $2 \mu \mathrm{g}$ ), nitrofurantoin (F; $300 \mu \mathrm{g})$, streptomycin (S; $10 \mu \mathrm{g})$, sulfamethoxazolo-trimethoprim (STX; $25 \mu \mathrm{g}$ ), sulfonamide (S3; $300 \mu \mathrm{g}$ ), tetracycline (TE; $30 \mu \mathrm{g}$ ), tigecycline (TGC; $15 \mu \mathrm{g})$, tobramycin (TOB; $10 \mu \mathrm{g}$ ) and trimethoprim $(\mathrm{W} ; 5 \mu \mathrm{g})$. The zone diameter interpretive criteria suggested by the CLSI were used [25]. Isolates that resulted resistant to at least one antibiotic in three different antimicrobial classes were considered as Multi-Drug Resistant (MDR) [26].

Presence of genes conferring resistance to ampicillin $\left(b l a_{T E M}, b l a_{P S E-1}\right)$, aminoglycosides (aadA1, aad $A 2$, aphA1-lab, str $A$-str $B)$, tetracyclines (tet $A$, tet $B$, tet $C$, tet $G)$ and sulfonamide (sul1, sul2, sul3) were evaluated with primers and protocols previously reported [27-31]. DNA previously extracted for detection of virulence genes was employed as a template in all single endpoint PCRs. 


\subsection{Statistical Analysis}

Data were analyzed with Student's $t$-test $(\mathrm{t})$, Chi-square $\left(\mathrm{X}^{2}\right)$ test and Fisher's $(\mathrm{F})$ test. The $t$-test was employed to verify if induction of gastric acid resistance causes a statistically significant difference in increase of survived cells. While, Chi-square $\left(X^{2}\right)$ and Fisher's $(F)$ tests were used to evaluate the distribution of genes, ACSSuT and MDR patterns among the different serotypes. Statistical significance threshold was set at a $p$-value $\leq 0.05$.

\section{Results}

Overall, 65 Salmonella spp. were isolated from analyzed samples. Regarding rectal swabs, 39/696 samples (5.6\%) resulted positive, whereas 26 Salmonella spp. were collected from 25/784 organs samples (3.19\%). In particular, 14 lymph node, 9 gut, 1 spleen and 1 liver samples resulted positive. Two different salmonellae, $S$. ser. Derby and $S$. ser. Typhimurium, were collected from one gut sample. Overall, 22/196 (11.22\%) animals were positive, Salmonella was isolated from both feces and lymph node of three animals.

The most detected serovar was $S$. ser. Derby, with 43 isolates. Seven isolates belonged to S. ser. Kapemba. Two isolates for each of the following serovars were detected: Infantis, Rissen, Bovismorbificans and Typhimurium Monophasic Variant (TMV). Two isolates, both from lymph nodes,

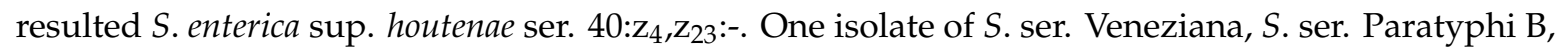
$S$. ser. London and $S$. ser. Typhimurium was detected. Finally, one isolate was found belonging to Group O4 (B), but it was not typable.

After PFGE analysis, 29 Salmonella spp. strains, including the 9 strains previously isolated, were selected. Table 1 reports information about the chosen strains.

Gastric acid survival challenge revealed that $13 / 29$ strains (44.83\%) showed both constitutive and inducible resistance, whereas 11/29 (37.93\%) strains survived the gastric acid environment only after induction. For 15/29 (51.72\%) isolates, the induction of resistance caused a significant $(p \leq 0.05)$ increase of gastric acid resistance (Table 1). Five out of 29 (17.24\%) isolates did not even exhibit resistance after induction. In Table 1, results of the gastric acid survival assay for each of the tested strains are reported.

As concerns the presence of virulence genes, the most detected genes were $\operatorname{sop} B, p i p B$ and $m g t C$, with $23 / 29(79.31 \%), 14 / 29(48.28 \%)$ and $11 / 29(37.93 \%)$ positive isolates, respectively. Genes sodCI, spvRBC, rhuM and gipA were found in less than about $20 \%$ of the strains (Table 2). None of the strains showed positivity for gene sopE. Four isolates resulted negative for all searched genes. Fourteen different virulence profiles were identified. None of the strains possessed all investigated genes, one $S$. ser. Typhimurium had 6 different genes, and 6 strains were positive for 5 different genes, as reported in Table 1.

No statistical differences were observed among distribution of virulence genes among investigated serotypes. To verify if serotype Typhimurium, including monophasic variant, is more virulent than others, isolates belonging to these serotypes were grouped together and compared with all others. In this case, most virulence genes ( $\operatorname{sod} C I, \operatorname{spv} R B C, r h u M, p i p B, m g t C$, gipA) resulted associated to Typhimurium and TMV, with a statistically significant difference $(p \leq 0.05)$. 
Table 1. Gastric acid resistance, virulence genes and antimicrobial resistance profiles of analyzed Salmonella spp. strains.

\begin{tabular}{|c|c|c|c|c|c|c|c|c|}
\hline \multirow{2}{*}{ Isolate } & \multirow[t]{2}{*}{ Serotype } & \multirow{2}{*}{ Source } & \multicolumn{2}{|c|}{$\begin{array}{c}\text { Gastric Environment } \\
\text { ResistanceMean Value } \pm \text { s.d. * }\end{array}$} & \multirow{2}{*}{ Virulence Genes Profile } & \multirow{2}{*}{$\begin{array}{c}\text { Antimicrobial } \\
\text { Resistance Profile }\end{array}$} & \multirow[t]{2}{*}{ MDR } & \multirow{2}{*}{$\begin{array}{c}\text { Antimicrobial Resistance } \\
\text { Genes }\end{array}$} \\
\hline & & & Constitutive & Induced & & & & \\
\hline S29 & Derby & I & $1.31 \pm 0.88$ & $10.15 \pm 3.18$ & sop $B$ & TE & & \\
\hline S34 & Derby & I & $4.39 \pm 1.87$ & $10.87 \pm 2.11^{\dagger}$ & sopB & S TE S3 & - & tet $A$ aad $A 1$ \\
\hline S76 & Derby & $\mathrm{L}$ & $0.00 \pm 0.00$ & $0.51 \pm 0.52$ & sopB mgtC & AMP KF K S TE S3 F & - & $b l a_{T E M} \operatorname{str} A-s t r B$ \\
\hline S77 & Mbandaka & I & $2.67 \pm 1.91$ & $4.64 \pm 3.38$ & $\operatorname{sop} B$ & TE TGC S3 & & \\
\hline S78 & Typhimurium & I & $3.68 \pm 2.79$ & $36.50 \pm 4.34^{\dagger}$ & spvRBC sopB rhuM pipB mgtC & NA AMP S TE TGC S3 & - & tetA bla $a_{T E M}$ strA-strB sul2 \\
\hline S79 & Give & I & $2.35 \pm 2.76$ & $8.12 \pm 2.26^{+}$ & $\operatorname{sop} B$ & TE TGC S3 W SXT & & strA-strB sul2 \\
\hline $\mathrm{S} 80$ & Livingstone & $\mathrm{L}$ & $0.00 \pm 0.00$ & $0.47 \pm 0.66$ & $\operatorname{sop} B$ & TE TGC S3 F & - & tet $A$ sul2 \\
\hline S82 & Infantis & LN & $0.00 \pm 0.00$ & $0.00 \pm 0.00$ & sоpB рірB & TE TGC S3 & & sul2 sul3 \\
\hline S83 & Typhimurium & I & $0.60 \pm 0.31$ & $0.53 \pm 0.61$ & sodCI spvRBC sopB rhuM pipB mgtC & NA AMP S TE S3 & $\bullet$ & tet $A$ bla $a_{T E M}$ strA-strB sul2 \\
\hline S99 & Choleraesuis & $\mathrm{L}$ & $0.00 \pm 0.00$ & $0.00 \pm 0.00$ & sodCI spvRBC sopB pipB gipA & S TE S3 & • & tet $A$ aad $A 2$ str $A$-str $B$ sul2 sul3 \\
\hline S100 & Typhimurium & I & $1.44 \pm 0.60$ & $1.26 \pm 1.10$ & sodCI sopB rhuM pipB mgtC & AMP S TE S3 & - & tetB tet $G$ bla $a_{\text {TEM }}$ strA-strB sul2 \\
\hline S169 & Kapemba & I & $0.31 \pm 0.16$ & $14.39 \pm 1.00^{\dagger}$ & $m g t C$ & $\mathrm{~S} 3$ & & \\
\hline S177 & Infantis & I & $0.67 \pm 0.02$ & $3.01 \pm 1.08$ & sopB pipB & AMP S S3 & - & \\
\hline S179 & Derby & I & $2.95 \pm 1.06$ & $64.20 \pm 2.81^{\dagger}$ & sopB & S3 & & \\
\hline S184 & Kapemba & $\mathrm{I}$ & $0.72 \pm 0.01$ & $23.29 \pm 3.98^{+}$ & & S3 & & \\
\hline S192 & Infantis & $\mathrm{Ie}$ & $0.10 \pm 0.12$ & $17.96 \pm 3.25^{+}$ & pipB & S S3 F & - & sul2 \\
\hline S193 & Derby & I & $6.02 \pm 5.47$ & $39.44 \pm 12.53^{\dagger}$ & & S3 & & \\
\hline S198 & Veneziana & I & $0.91 \pm 0.56$ & $29.71 \pm 0.16^{+}$ & & & & \\
\hline S203 & Group 4 & I & $6.01 \pm 5.69$ & $32.71 \pm 10.50^{\dagger}$ & & $\mathrm{F}$ & & \\
\hline S272 & Derby & I & $5.61 \pm 1.80$ & $43.18 \pm 1.24^{\dagger}$ & $\operatorname{sop} B$ & & & \\
\hline S276 & Rissen & I & $13.19 \pm 3.71$ & $13.81 \pm 1.42$ & $\operatorname{sop} B$ & TE & & tet $A$ \\
\hline S293 & Bovismorbificans & LN & $0.21 \pm 0.16$ & $3.85 \pm 0.54^{\dagger}$ & sodCI spvRBC sopB pipB & & & \\
\hline S311 & Paratyphi B & LN & $0.66 \pm 0.28$ & $6.04 \pm 0.21^{\dagger}$ & sopB pipB mgtC & $\mathrm{S}$ & & \\
\hline S315 & Derby & $\mathrm{LN}$ & $3.98 \pm 1.75$ & $2.54 \pm 2.06$ & sopB pipB mgtC & S TOB TE S3 & - & tet $A$ aad $A 2$ \\
\hline S317 & London & I & $0.03 \pm 0.02$ & $6.48 \pm 1.38^{+}$ & sopB pipB mgtC & AMP TE TGC S3 F & $\bullet$ & aadA2 \\
\hline S322 & Typhimurium & I & $0.04 \pm 0.04$ & $3.98 \pm 0.55^{+}$ & sodCI spvRBC sopB pipB mgtC & AMP S TE TGC S3 C & - & tet $A$ tet $G$ aad $A 2$ sul1 \\
\hline S324 & $40: \mathrm{z}_{4}, \mathrm{z}_{23}:-$ & LN & $0.53 \pm 0.13$ & $1.32 \pm 0.52$ & spvRBC sopB & S AK S3 & & \\
\hline S327 & TMV & I & $0.34 \pm 0.08$ & $4.64 \pm 1.12$ & sopB rhuM pipB mgtC gip $A$ & AMP S S3 F & - & tetB bla $a_{T E M}$ strA-strB sul2 \\
\hline S333 & TMV & I & $1.55 \pm 0.60$ & $4.54 \pm 0.61$ & sopB rhuM pipB mgtC gip $A$ & AMP S TE S3 F & $\bullet$ & tetB bla $a_{T E M}$ strA-strB sul2 \\
\hline
\end{tabular}


Table 2. Distribution of virulence genes among different analyzed Salmonella spp. strains.

\begin{tabular}{|c|c|c|c|c|c|c|c|c|}
\hline \multirow{2}{*}{ Serotype (No. of Analyzed Strains) } & \multicolumn{8}{|c|}{ Virulence Genes } \\
\hline & $\operatorname{sodCI}$ & sopE & $s p v R B C$ & $\operatorname{sopB}$ & rhuM & pipB & mgtC & gipA \\
\hline Bovismorbificans (1) & 1 & 0 & 1 & 1 & 0 & 1 & 0 & 0 \\
\hline Choleraesuis (1) & 1 & 0 & 1 & 1 & 0 & 1 & 0 & 1 \\
\hline Derby (7) & 0 & 0 & 0 & 6 & 0 & 1 & 2 & 0 \\
\hline Give (1) & 0 & 0 & 0 & 1 & 0 & 0 & 0 & 0 \\
\hline Group 4 (1) & 0 & 0 & 0 & 0 & 0 & 0 & 0 & 0 \\
\hline Infantis (3) & 0 & 0 & 0 & 2 & 0 & 3 & 0 & 0 \\
\hline Kapemba (2) & 0 & 0 & 0 & 0 & 0 & 0 & 1 & 0 \\
\hline Livingstone (1) & 0 & 0 & 0 & 1 & 0 & 0 & 0 & 0 \\
\hline London (1) & 0 & 0 & 0 & 1 & 0 & 1 & 1 & 0 \\
\hline Mbandaka (1) & 0 & 0 & 0 & 1 & 0 & 0 & 0 & 0 \\
\hline Paratyphi B (1) & 0 & 0 & 0 & 1 & 0 & 1 & 1 & 0 \\
\hline Rissen (1) & 0 & 0 & 0 & 1 & 0 & 0 & 0 & 0 \\
\hline Typhimurium (4) & 3 & 0 & 3 & 4 & 3 & 4 & 4 & 0 \\
\hline TMV (2) & 0 & 0 & 0 & 2 & 2 & 2 & 2 & 2 \\
\hline Veneziana (1) & 0 & 0 & 0 & 0 & 0 & 0 & 0 & 0 \\
\hline $40: z_{4}, z_{23}:-(1)$ & 0 & 0 & 1 & 1 & 0 & 0 & 0 & 0 \\
\hline Total (29) & 5 & 0 & 6 & 23 & 5 & 14 & 11 & 3 \\
\hline
\end{tabular}

Table 3. Antimicrobial resistance of Salmonella spp. strains.

\begin{tabular}{|c|c|c|c|c|c|c|c|c|c|}
\hline \multirow{2}{*}{ Antimicrobial } & & \multicolumn{2}{|c|}{ Susceptible } & \multicolumn{2}{|c|}{ Intermediate } & \multicolumn{2}{|c|}{ Resistant } & \multicolumn{2}{|c|}{ Non-Susceptible } \\
\hline & & No. & $\%$ & No. & $\%$ & No. & $\%$ & No. & $\%$ \\
\hline \multirow{3}{*}{ Fluoroquinolones } & NA & 26 & 89.66 & 1 & 3.45 & 2 & 6.90 & 3 & 10.34 \\
\hline & CIP & 27 & 93.10 & 2 & 6.90 & 0 & 0.00 & 2 & 6.90 \\
\hline & ENR & 24 & 82.76 & 5 & 17.24 & 0 & 0.00 & 5 & 17.24 \\
\hline \multirow{2}{*}{ Penicillins } & AMP & 17 & 58.62 & 3 & 10.34 & 9 & 31.03 & 12 & 41.38 \\
\hline & AMC & 27 & 93.10 & 2 & 6.90 & 0 & 0.00 & 2 & 6.90 \\
\hline \multirow{3}{*}{ Cephems (cephalosporins) } & CTX & 24 & 82.76 & 5 & 17.24 & 0 & 0.00 & 5 & 17.24 \\
\hline & $\mathrm{KF}$ & 24 & 82.76 & 4 & 13.79 & 1 & 3.45 & 5 & 17.24 \\
\hline & CAZ & 29 & 100.00 & 0 & 0.00 & 0 & 0.00 & 0 & 0.00 \\
\hline \multirow{5}{*}{ Aminoglycosides } & $\mathrm{CN}$ & 29 & 100.00 & 0 & 0.00 & 0 & 0.00 & 0 & 0.00 \\
\hline & $\mathrm{K}$ & 12 & 41.38 & 16 & 55.17 & 1 & 3.45 & 17 & 58.62 \\
\hline & $\mathrm{S}$ & 3 & 10.34 & 12 & 41.38 & 14 & 48.28 & 26 & 89.66 \\
\hline & $\mathrm{AK}$ & 26 & 89.66 & 2 & 6.90 & 1 & 3.45 & 3 & 10.34 \\
\hline & TOB & 21 & 72.41 & 7 & 24.14 & 1 & 3.45 & 8 & 27.59 \\
\hline \multirow{2}{*}{ Tetracyclines } & $\mathrm{TE}$ & 12 & 41.38 & 1 & 3.45 & 15 & 51.72 & 16 & 57.14 \\
\hline & TGC & 1 & 3.45 & 21 & 72.41 & 7 & 24.14 & 28 & 96.55 \\
\hline \multirow{3}{*}{ Folate pathway inhibitors } & S3 & 6 & 20.69 & 1 & 3.45 & 22 & 75.86 & 23 & 79.31 \\
\hline & $\mathrm{W}$ & 28 & 96.55 & 0 & 0.00 & 1 & 3.45 & 1 & 3.45 \\
\hline & SXT & 28 & 96.55 & 0 & 0.00 & 1 & 3.45 & 1 & 3.45 \\
\hline \multirow{4}{*}{ Others } & CT & 29 & 100.00 & 0 & 0.00 & 0 & 0.00 & 0 & 0.00 \\
\hline & $\mathrm{F}$ & 16 & 55.17 & 6 & 20.69 & 7 & 24.14 & 13 & 44.83 \\
\hline & C & 27 & 93.10 & 1 & 3.45 & 1 & 3.45 & 2 & 6.90 \\
\hline & FFC & 26 & 89.66 & 3 & 10.34 & 0 & 0.00 & 3 & 10.34 \\
\hline
\end{tabular}

Legend: $\mathrm{AMC}=$ amoxicillin-clavulanic acid, $\mathrm{AMP}=$ ampicillin, $\mathrm{AK}=$ amikacin, $\mathrm{KF}=$ cephalothin, $\mathrm{CTX}=$ cefotaxime, $\mathrm{CAZ}=$ ceftazidime, $\mathrm{C}=$ chloramphenicol, $\mathrm{CIP}=$ ciprofloxacin, $\mathrm{CT}=$ colistin, $\mathrm{ENR}=$ enrofloxacin, $\mathrm{FFC}=$ florphenicol, $\mathrm{CN}=$ gentamycin, $\mathrm{K}=$ kanamycin, $\mathrm{NA}=$ nalidixic acid, $\mathrm{F}=$ nitrofurantoin, $\mathrm{S}=$ streptomycin, $\mathrm{STX}=$ sulfamethoxazolo-trimethoprim, $\mathrm{S} 3=$ sulfonamide, $\mathrm{TE}=$ tetracycline, $\mathrm{TGC}=$ tigecycline, $\mathrm{TOB}=$ tobramycin, W trimethoprim. 
A high percentage of antimicrobial resistance was observed for sulfonamide, 22/29 (75.86\%) resistant strains, tetracycline, 15/29 (51.72\%) resistant strains, and streptomycin, 14/29 (48.28\%) resistant strains. All tested salmonellae were susceptible to ceftazidime, gentamycin and colistin sulfate. A high percentage of strains $(\geq 90 \%)$ resulted susceptible to ciprofloxacin, amoxicillin/clavulanic acid, trimethoprim, sulfamethoxazole/trimethoprim and chloramphenicol. Table 3 reports the percentage of susceptible, intermediate and resistant strains for each of the antimicrobials employed. Three strains were susceptible to all antimicrobials tested. Twenty different resisto-types were identified (Table 1). MDR was observed in 14/29 (48.27\%) of the analyzed isolates (Table 1). Six strains showed the ASSuT (Ampicillin, Streptomycin, Sulfonamide, Tetracycline) profile and one of them was also resistant to chloramphenicol (Table 1).

No statistical differences were observed about the distribution of ASSuT profile and MDR among the different serotypes. Considering Typhimurium and TMV more tightly and comparing isolates belonging to these serotypes with all other isolates, the ASSuT profile and MDR resulted associated to the these serotypes, with a statistically significant difference $(p \leq 0.05)$.

As regards antimicrobial resistance genes, genes more often detected were $s u l 2,10 / 29$ (34.48\%) positive isolates, tet $A, 8 / 29(27.58 \%)$ positive isolates, $\operatorname{str} A-s t r B, 8 / 29(27.58 \%)$ positive isolates, and $b l a_{T E M}$, $6 / 29(20.68 \%)$ positive isolates. None of the tested salmonellae resulted positive for bla $a_{P S E-1}$, tetC and aphA1-lab. Table 4 reports the distribution of resistance genes among the different serovars. Thirteen out of twenty-two isolates did not present resistance genes, while 6/29 salmonellae showed 3 or more different genes (Table 1).

No statistical differences were observed among distribution of resistance genes among different serotypes. However, grouping isolates belonging to serotypes Typhimurium and TMV together and comparing them with all other serotypes, the genes tet $B, \operatorname{tet} G, b l a_{T E M}, \operatorname{str} A$-str $B$, sull and sul2 resulted significantly $(p \leq 0.05)$ associated to serotypes Typhimurium and TMV. 
Table 4. Distribution of antimicrobial resistance genes among analyzed Salmonella spp. strains.

\begin{tabular}{|c|c|c|c|c|c|c|c|c|c|c|c|c|c|}
\hline \multirow{2}{*}{ Serotype (No. of Analyzed Strains) } & \multicolumn{13}{|c|}{ Resistance Genes } \\
\hline & tet $A$ & tetB & tetC & tet $G$ & $\operatorname{aadA1}$ & $\operatorname{aad} A 2$ & aphA1-lab & strA-strB & bla $_{T E M}$ & bla $_{P S E-1}$ & sul1 & sul2 & sul3 \\
\hline Bovismorbificans (1) & 0 & 0 & 0 & 0 & 0 & 0 & 0 & 0 & 0 & 0 & 0 & 0 & 0 \\
\hline Choleraesuis (1) & 1 & 0 & 0 & 0 & 0 & 1 & 0 & 1 & 0 & 0 & 0 & 1 & 1 \\
\hline Derby (7) & 2 & 0 & 0 & 0 & 1 & 1 & 0 & 1 & 1 & 0 & 0 & 0 & 0 \\
\hline Give (1) & 0 & 0 & 0 & 0 & 0 & 0 & 0 & 1 & 0 & 0 & 0 & 1 & 0 \\
\hline Group 4 (1) & 0 & 0 & 0 & 0 & 0 & 0 & 0 & 0 & 0 & 0 & 0 & 0 & 0 \\
\hline Infantis (3) & 0 & 0 & 0 & 0 & 0 & 0 & 0 & 0 & 0 & 0 & 0 & 2 & 1 \\
\hline Kapemba (2) & 0 & 0 & 0 & 0 & 0 & 0 & 0 & 0 & 0 & 0 & 0 & 0 & 0 \\
\hline Livingstone (1) & 1 & 0 & 0 & 0 & 0 & 0 & 0 & 0 & 0 & 0 & 0 & 1 & 0 \\
\hline London (1) & 0 & 0 & 0 & 0 & 0 & 1 & 0 & 0 & 0 & 0 & 0 & 0 & 0 \\
\hline Mbandaka (1) & 0 & 0 & 0 & 0 & 0 & 0 & 0 & 0 & 0 & 0 & 0 & 0 & 0 \\
\hline Paratyphi B (1) & 0 & 0 & 0 & 0 & 0 & 0 & 0 & 0 & 0 & 0 & 0 & 0 & 0 \\
\hline Rissen (1) & 1 & 0 & 0 & 0 & 0 & 0 & 0 & 0 & 0 & 0 & 0 & 0 & 0 \\
\hline Typhimurium (4) & 3 & 1 & 0 & 2 & 0 & 1 & 0 & 3 & 3 & 0 & 1 & 3 & 0 \\
\hline TMV (2) & 0 & 2 & 0 & 0 & 0 & 0 & 0 & 2 & 2 & 0 & 0 & 2 & 0 \\
\hline Veneziana (1) & 0 & 0 & 0 & 0 & 0 & 0 & 0 & 0 & 0 & 0 & 0 & 0 & 0 \\
\hline $40: z_{4}, z_{23}:-(1)$ & 0 & 0 & 0 & 0 & 0 & 0 & 0 & 0 & 0 & 0 & 0 & 0 & 0 \\
\hline Total (29) & 8 & 3 & 0 & 2 & 1 & 4 & 0 & 8 & 6 & 0 & 1 & 10 & 2 \\
\hline
\end{tabular}




\section{Discussion}

In this work, virulence traits of Salmonella spp. isolated from swine were evaluated. The acquisition of epidemiological information was not a primary objective of the study; however, some consideration could be carried out. The percentage of positive animals detected was in accordance with other works; in particular, the European Food Safety Authority (EFSA) report showed a prevalence in pigs of $3.5 \%$, ranging from $0 \%$ to $10.6 \%$, in Europe in 2016 [32]. Other recent works conducted in Italy and Europe reported Salmonella prevalence in pigs ranging from about $10 \%$ to $20 \%$ [2,33,34]. As expected, lymph nodes represented the best samples for Salmonella detection, showing the highest percentage of positive results, however the simultaneous investigation on feces, LN, spleen and liver considerably increased the chances to detect positive animals. Salmonella ser. Derby was the most detected serovar. This evidence could be considered predictable, because it was one of the serovars most often detected in swine [1,2,32-34]. However, it is interesting to note that some atypical salmonellae were isolated, in particular, S. ser. Paratyphi B and S. enterica sup. houtenae ser. 40:z4,z23:-, from lymph nodes.

Stomach represents the primary physical barrier that foodborne pathogens must overcome. Resistance to the gastric acid environment could represent a great advantage. In this study, $44.83 \%$ of analyzed strains showed constitutive resistance to the gastric acid environment. Moreover, $37.93 \%$ of strains became resistant only after exposure to middle-low $\mathrm{pH}$ (5.5). In many cases, the percentage of survived cells greatly improved after induction. In particular, for more than half of isolates, a significant increase of survived cells to Synthetic Gastric Juice (SGJ) was registered after pre-exposure to middle-low $\mathrm{pH}$. In Italy, pig meat is widely employed for the production of fresh sausage, and these products reach low $\mathrm{pH}$ values during maturation [35]. This environmental condition could induce gastric acid resistance and promote the transit through the stomach for some strains and represent a great advantage for these foodborne pathogens.

The gene sopB, located on SPI5, was detected in most of the analyzed strains (79.31\%). It is involved in intestinal cells' invasion and fluid secretion and it is frequently detected in clinical isolates of Salmonella [36]. Also pipB is located on SPI5, but it is involved in the survival of salmonellae inside host cells, and it is important for systemic dissemination and establishment of carrier state [37]. A percentage of $48.28 \%$ of the analyzed strains possessed pipB. The third most detected gene was $m g t C$, with $37.93 \%$ of positive isolates. This gene is located on SPI3, it is involved in survival of salmonellae in the phagosome environment and it is commonly found in clinical isolates [38]. The gene rhuM, involved in systemic dissemination and located on SPI3, was detected in a low number of isolates (17.24\%), always in association with $m g t C$. This gene is not frequently found in Salmonella field isolates, as suggested by other authors [39]. Salmonella virulence plasmid (spv) is involved in systemic dissemination and it is typical of septicemic and more virulent strains [9]. In our study, spv was detected in a few isolates (20.69\%): in all but one S. ser. Typhimurium, in S. ser. Bovismorbificans and in S. ser. Choleraesuis strains. Surprisingly, it was also detected in S. enterica sup. houtenae ser. 40: $\mathrm{z}_{4}, \mathrm{z}_{23}$ :- - salmonellae belonging to subspecies houtenae are generally considered low pathogenic and rarely involved in animal and human diseases [1,32]. However, spv could sometimes be detected in salmonellae other than subspecies enterica [16], and isolation of this strain from lymph nodes confirms its ability to cause systemic infection. The virulence gene sodCI, located on a prophage, is involved in protection of Salmonella from oxidative burst inside macrophage; this gene, important for systemic dissemination and septicemic disease, is generally found in most virulent strains $[10,20]$. A percentage of $17.24 \%$ of the isolates resulted sodCI-positive; in particular, $S$. ser. Bovismorbificans, S. ser. Choleraesuis and all but one S. ser. Typhimurium. Finally, gipA was detected in 3/29 (10.34\%) isolates: S. ser. Choleraesuis and the $2 \mathrm{~S}$. ser. TMV. This gene, involved in invasion of the M cells in the Peyer's Patch, is not frequently found in Salmonella strains $[7,40]$. None of the analyzed isolates resulted positive for sopE. This gene, involved in intestinal invasion and fluid secretion, is more often detected in serovar Enteritidis [40].

Four out of the twenty-nine strains were negative for all the investigated genes $(1 \mathrm{~S}$. ser. Derby, $1 S$. ser. Kapemba, $1 \mathrm{~S}$. ser. Veneziana and the not typable strain). None of the isolates resulted positive 
for all 8 targeted genes, but 1 isolate, S. ser. Typhimurium, was positive for 6 genes, and 6 isolates, 3 S. ser. Typhimurium, 2 S. ser. TMV and $S$. ser. Choleraesuis, scored positive for 5 genes. Overall, 15 different virulence profiles were detected, highlighting the great variability that could be encountered in field isolates. Statistical analyses seem to suggest that virulence genes are more often associated to serotypes Typhimurium and TMV, confirming the high virulence and pathogenicity of salmonellae belonging to these serovars. Furthermore, the rare report of the other serovars in humans could be linked to their low virulence. Indeed, without the presence of a passive control system, only clinical cases, that require care or hospitalization, are generally notified in humans. It is possible that many infections by less virulent strains, circulating among animals, occurred in humans, not evolving into clinical disease.

The last characteristic evaluated was antimicrobial resistance. Three molecules, ceftazidime, gentamycin and colistin sulfate, resulted effective against all tested strains. None of the isolates were fully resistant to ciprofloxacin and cefotaxime, which are the clinically most important antimicrobials for treatment of human salmonellosis [12]. The highest percentage of resistance was recorded for sulfonamide, with $75.86 \%$ of resistant isolates. Sulfonamide compounds are largely used in farm animals and resistance to Salmonella is frequently detected [34,41]. A percentage of $51.72 \%$ of strains resulted resistant to tetracycline: this antimicrobial is commonly used in veterinary medicine for treatment of bacterial diseases and in the past years, its effectiveness has been decreasing considerably $[12,13,34]$. High resistance was also detected for streptomycin: $48.28 \%$ and $41.38 \%$ of resistant and intermediate strains, respectively. A low level of resistance to the other aminoglycoside compounds tested was encountered, except for kanamycin, with $58.62 \%$ of non-susceptible isolates. These data are in agreement with recent reports focused on antimicrobial resistance of salmonellae isolated from swine [34,41]. Low susceptibility was also detected for tigecycline, nitrofurantoin and ampicillin: $96.55 \%, 44.83 \%$ and $41.38 \%$ of non-susceptible strains, respectively. Concerning tigecycline, only $24.14 \%$ resulted resistant, whereas $72.41 \%$ were classified as intermediate. It is a broad-spectrum antimicrobial recently approved for human treatment, however different studies underlined the emergence of resistant isolates among Salmonella $[40,42]$. Use of nitrofurantoin in food-producing animals has been illegal since the early nineties of the last century; however, resistance among Salmonella isolates was frequently detected [43]. Finally, different authors reported a worrying increase of ampicillin resistance in Salmonella isolates from swine and humans $[12,13,34,43]$. Only 3/29 strains resulted susceptible to all antimicrobials tested, $S$. ser. Veneziana, $S$. ser. Bovismorbificans and $1 S$. ser. Derby, while the other strains were resistant to from 1 to 7 different antimicrobials. In particular, 1 strain, $S$. ser. Derby, was resistant to 7 antimicrobials, 2 strains, both belonging to $S$. ser. Typhimurium, were resistant to 6 antimicrobials, and 4 strains, 1 S. ser. Give, 1 S. ser. London, 1 S. ser. Typhimurium and 1 S. ser. TMV, resulted resistant to 5 different compounds. Multi-Drug-Resistant isolates were $48.27 \%$ of the total, and his value was in line with the last EFSA report on antimicrobial resistance, where the reported percentage of MDR Salmonella strains isolates from pigs was 47.4\% [13]. ASSuT and ACSSuT profiles, often associated to more virulent strains [14], were detected in five strains, 3 S. ser. Typhimurium, 1 S. ser. Derby and $1 S$. ser. TMV, and one, $S$. ser. Typhimurium isolate, respectively.

As expected, considering phenotypic profiles, antimicrobial resistance genes conferring resistance for sulfonamides, aminoglycosides and tetracyclines were the most detected. Twelve out of twenty-nine $(41.37 \%)$ isolates harbored sul genes alone or in combination, $12 / 29(41.37 \%)$ had at least one aminoglycosides resistance gene, while 11/29 (37.93\%) isolates scored positive for one or more tet genes. The gene sul3 was rarely reported in Salmonella, in accordance with present data [44,45]. The gene sul2 resulted more present that sul1 in analyzed isolates, while other authors reported the two genes equally diffused among Salmonella [44,45]. This could be linked to the origin of the samples, indeed, among pigs, it seems sul2 is more frequently detected than sul1 [46]. Among aminoglycosides resistance genes, str $A$-str $B$ was the most detected, and this gene was frequently detected in streptomycin-resistant salmonellae. All but one, $S$. ser. Choleraesuis, positive isolates scored positive for only one of the searched aminoglycosides resistance genes $[47,48]$. tet $A$ was confirmed as the more frequent 
tetracycline resistance gene present among Salmonella $[47,49,50]$. Presence of $b l a_{T E M}$ explained the resistance to Ampicillin in all but 2 resistant isolates. This gene was frequently detected among Salmonella $[48,49]$. Almost all gene-positive isolates were phenotypically resistant to the respective antimicrobials. However, some resistant isolates did not score positive for the searched genes. This is probably related to the presence of other resistance genes in the analyzed salmonellae. Some serotypes, in particular Typhimurium and Typhimurium Monophasic Variant, resulted positive more often for more than one gene. Also, for antimicrobial resistance, ASSuT profile, MDR and resistance genes resulted more associated to serotypes Typhimurium and TMV, observations confirmed by statistical analyses. These findings add other "weapons" to the "arsenal" of these serotypes, and probably contribute to explaining why infection by these serotypes needs particular antimicrobial treatment and sometimes hospitalization, and it stresses the fact that they are more dangerous for human health.

\section{Conclusions}

The obtained results highlight that a great variability exists among Salmonella serovars and strains circulating in swine. Although it is not possible to draw up a ranking, some serovars resulted more virulent than others; in particular, the isolates belonging to $S$. ser. Typhimurium exhibited many of the pathogenic traits investigated, and these evidences confirm Typhimurium as one of the most virulent serovars. This study underlines and confirms that many virulent Salmonella strains circulate among pigs and that swine represent a source of pathogenic salmonellae for humans.

Author Contributions: Conceptualization, F.F., V.V.E. and F.B.; Data curation, H.N.T., T.-T.-T.P. and B.T.; Formal analysis, F.B.; Investigation, H.N.T., T.-T.-T.P. and F.B.; Methodology, H.N.T., T.-T.-T.P. and F.B.; Resources, F.F., V.V.E. and D.C.; Writing-original draft, B.T. and F.B.; Writing-review and editing, H.N.T., T.-T.-T.P., B.T., F.F., V.V.E., D.C. and F.B. All authors have read and agreed to the published version of the manuscript.

Funding: This research has been supported by grants of the University of Pisa.

Acknowledgments: The authors wish to thank the colleagues of the "Istituto Zooprofilattico Sperimentale Lazio e Toscana, sezione di Roma", that serotyped the Salmonella spp. isolates.

Conflicts of Interest: The authors declare no conflict of interest.

\section{References}

1. EFSA, (European Food Safety Authority); ECDC, (European Centre for Disease Prevention and Control). The European Union One Health 2018 Zoonoses Report. EFSA J. 2019, 17, 276.

2. Denis, M.; Houard, E.; Fablet, A.; Rouxel, S.; Salvat, G. Distribution of serotypes and genotypes of Salmonella enterica species in French pig production. Vet. Rec. 2013, 173, 370. [CrossRef] [PubMed]

3. Audia, J.P.; Webb, C.C.; Foster, J.W. Breaking through the acid barrier: An orchestrated response to proton stress by enteric bacteria. Int. J. Med. Microbiol. 2001, 291, 97-106. [CrossRef] [PubMed]

4. Santos, R.L.; Tsolis, R.M.; Bäumler, A.J.; Adams, L.G. Pathogenesis of Salmonella-induced enteritis. Braz. J. Med. Biol. Res. 2003, 36, 3-12. [CrossRef]

5. Hensel, M. Evolution of pathogenicity islands of Salmonella enterica. Int. J. Med. Microbiol. 2004, 294, 95-102. [CrossRef] [PubMed]

6. Gerlach, R.G.; Hensel, M. Salmonella pathogenicity islands in host specificity, host pathogen-interactions and antibiotics resistance of Salmonella enterica. Berl. Münch. Tierärztl. Wochenschr. 2007, 120, 317-327. [PubMed]

7. Stanley, T.L.; Ellermeier, C.D.; Slauch, J.M. Tissue-specific gene expression identifies a gene in the lysogenic phage Gifsy-1 that affects Salmonella enterica serovar typhimurium survival in Peyer's patches. J. Bacteriol. 2000, 182, 4406-4413. [CrossRef]

8. Ehrbar, K.; Hardt, W.-D. Bacteriophage-encoded type III effectors in Salmonella enterica subspecies 1 serovar Typhimurium. Infect. Genet. Evol. 2005, 5, 1-9. [CrossRef]

9. Guiney, D.G.; Fierer, J. The role of the spv genes in Salmonella pathogenesis. Front. Microbiol. 2011, 2, 129. [CrossRef] 
10. Rushing, M.D.; Slauch, J.M. Either periplasmic tethering or protease resistance is sufficient to allow a SodC to protect Salmonella enterica serovar Typhimurium from phagocytic superoxide. Mol. Microbiol. 2011, 82, 952-963. [CrossRef]

11. Brunelle, B.W.; Bearson, B.L.; Bearson, S.M.D. Chloramphenicol and tetracycline decrease motility and increase invasion and attachment gene expression in specific isolates of multidrug-resistant Salmonella enterica serovar Typhimurium. Front. Microbiol. 2015, 5, 801. [CrossRef] [PubMed]

12. EFSA. The European Union summary report on antimicrobial resistance in zoonotic and indicator bacteria from humans, animals and food in 2015. EFSA J. 2017, 15, 4694.

13. EFSA, (European Food Safety Authority); ECDC, (European Centre for Disease Prevention and Control). The European Union summary report on antimicrobial resistance in zoonotic and indicator bacteria from humans, animals and food in 2017/2018. EFSA J. 2020, 18, 6007.

14. Graziani, C.; Busani, L.; Dionisi, A.M.; Lucarelli, C.; Owczarek, S.; Ricci, A.; Mancin, M.; Caprioli, A.; Luzzi, I. Antimicrobial resistance in Salmonella enterica serovar Typhimurium from human and animal sources in Italy. Vet. Microbiol. 2008, 128, 414-418. [CrossRef]

15. McMillan, E.A.; Gupta, S.K.; Williams, L.E.; Jové, T.; Hiott, L.M.; Woodley, T.A.; Barrett, J.B.; Jackson, C.R.; Wasilenko, J.L.; Simmons, M.; et al. Antimicrobial resistance genes, cassettes, and plasmids present in salmonella enterica associated with United States food animals. Front. Microbiol. 2019, 10, 832. [CrossRef]

16. Bertelloni, F.; Chemaly, M.; Cerri, D.; Le Gall, F.; Ebani, V.V. Salmonella infection in healthy pet reptiles: Bacteriological isolation and study of some pathogenic characters. Acta Microbiol. Immunol. Hung. 2016, 63, 203-216. [CrossRef]

17. Kérouanton, A.; Marault, M.; Lailler, R.; Weill, F.-X.; Feurer, C.; Espié, E.; Brisabois, A. Pulsed-field gel electrophoresis subtyping database for foodborne Salmonella enterica serotype discrimination. Foodborne Pathog. Dis. 2007, 4, 293-303. [CrossRef]

18. Xia, X.; Zhao, S.; Smith, A.; McEvoy, J.; Meng, J.; Bhagwat, A.A. Characterization of Salmonella isolates from retail foods based on serotyping, pulse field gel electrophoresis, antibiotic resistance and other phenotypic properties. Int. J. Food Microbiol. 2009, 129, 93-98. [CrossRef]

19. Skyberg, J.A.; Logue, C.M.; Nolan, L.K. Virulence genotyping of Salmonella spp. with multiplex PCR. Avian Dis. 2006, 50, 77-81. [CrossRef]

20. Karasova, D.; Havlickova, H.; Sisak, F.; Rychlik, I. Deletion of sodCI and spvBC in Salmonella enterica serovar Enteritidis reduced its virulence to the natural virulence of serovars Agona, Hadar and Infantis for mice but not for chickens early after infection. Vet. Microbiol. 2009, 139, 304-309. [CrossRef]

21. Huehn, S.; La Ragione, R.M.; Anjum, M.; Saunders, M.; Woodward, M.J.; Bunge, C.; Helmuth, R.; Hauser, E.; Guerra, B.; Beutlich, J.; et al. Virulotyping and antimicrobial resistance typing of Salmonella enterica serovars relevant to human health in Europe. Foodborne Pathog. Dis. 2010, 7, 523-535. [CrossRef] [PubMed]

22. Paban Bhowmick, P.; Devegowda, D.; Karunasagar, I. Virulotyping of seafood associated Salmonella enterica subsp. enterica isolated from Southwest coast of India. Res. Artic. Biotechnol. Bioinf. Bioeng. 2011, 1, $63-69$.

23. Parvathi, A.; Vijayan, J.; Murali, G.; Chandran, P. Comparative virulence genotyping and antimicrobial susceptibility profiling of environmental and clinical Salmonella enterica from Cochin, India. Curr. Microbiol. 2011, 62, 21-26. [CrossRef] [PubMed]

24. Clinical and Laboratory Standards Institute (CLSI). M02-A12 Performance Standards for Antimicrobial Disk Susceptibility Tests; Clinical and Laboratory Standards Institute: Wayne, PA, USA, 2015.

25. CLSI. Performance Standards for Antimicrobial Disk and Dilution Susceptibility Tests for Bacteria Isolated from Animals, 3rd ed.; Clinical and Laboratory Standards Institute: Wayne, PA, USA, 2008.

26. Magiorakos, A.P.; Srinivasan, A.; Carey, R.B.; Carmeli, Y.; Falagas, M.E.; Giske, C.G.; Harbarth, S.; Hindler, J.F.; Kahlmeter, G.; Olsson-Liljequist, B.; et al. Multidrug-resistant, extensively drug-resistant and pandrug-resistant bacteria: An international expert proposal for interim standard definitions for acquired resistance. Clin. Microbiol. Infect. 2012, 18, 268-281. [CrossRef] [PubMed]

27. Dahshan, H.; Shahada, F.; Chuma, T.; Moriki, H.; Okamoto, K. Genetic analysis of multidrug-resistant Salmonella enterica serovars Stanley and Typhimurium from cattle. Vet. Microbiol. 2010, 145, 76-83. [CrossRef] [PubMed]

28. Benacer, D.; Thong, K.L.; Watanabe, H.; Devi Puthucheary, S. Characterization of drug-resistant Salmonella enterica serotype Typhimurium by antibiograms, plasmids, integrons, resistance genes, and PFGE. J. Microbiol. Biotechnol. 2010, 20, 1042-1052. [PubMed] 
29. Barlozzari, G.; Franco, A.; Macrì, G.; Lorenzetti, S.; Maggiori, F.; Dottarelli, S.; Maurelli, M.; Di Giannatale, E.; Tittarelli, M.; Battisti, A.; et al. First report of Brucella suis biovar 2 in a semi free-range pig farm, Italy. Vet. Ital. 2015, 51, 151-154.

30. Costa, D.; Poeta, P.; Sáenz, Y.; Vinué, L.; Coelho, A.C.; Matos, M.; Rojo-Bezares, B.; Rodrigues, J.; Torres, C. Mechanisms of antibiotic resistance in Escherichia coli isolates recovered from wild animals. Microb. Drug Resist. 2008, 14, 71-77. [CrossRef]

31. Maynard, C.; Fairbrother, J.M.; Bekal, S.; Sanschagrin, F.; Levesque, R.C.; Brousseau, R.; Masson, L.; Larivière, S.; Harel, J. Antimicrobial resistance genes in enterotoxigenic Escherichia coli O149: K91 isolates obtained over a 23-year period from pigs. Antimicrob. Agents Chemother. 2003, 47, 3214-3221. [CrossRef]

32. EFSA. The European Union summary report on trends and sources of zoonoses, zoonotic agents and food-borne outbreaks in 2016. EFSA J. 2017, 15, 5077.

33. Bonardi, S.; Bassi, L.; Brindani, F.; D’Incau, M.; Barco, L.; Carra, E.; Pongolini, S. Prevalence, characterization and antimicrobial susceptibility of Salmonella enterica and Yersinia enterocolitica in pigs at slaughter in Italy. Int. J. Food Microbiol. 2013, 163, 248-257. [CrossRef] [PubMed]

34. Bonardi, S.; Alpigiani, I.; Bruini, I.; Barilli, E.; Brindani, F.; Morganti, M.; Cavallini, P.; Bolzoni, L.; Pongolini, S. Detection of Salmonella enterica in pigs at slaughter and comparison with human isolates in Italy. Int. J. Food Microbiol. 2016, 218, 44-50. [CrossRef] [PubMed]

35. Torrieri, E.; Russo, F.; Di Monaco, R.; Cavella, S.; Villani, F.; Masi, F. Shelf life prediction of fresh Italian pork sausage modified atmosphere packed. Food Sci. Technol. Int. 2011, 17, 223-232. [CrossRef] [PubMed]

36. Rahman, H. Prevalence \& phenotypic expression of sopB gene among clinical isolates of Salmonella enterica. Indian J. Med. Res. 2006, 123, 83-88.

37. Núñez-Hernández, C.; Alonso, A.; Pucciarelli, M.G.; Casadesús, J.; García-del Portillo, F. Dormant intracellular Salmonella enterica serovar Typhimurium discriminates among Salmonella pathogenicity island 2 effectors to persist inside fibroblasts. Infect. Immun. 2014, 82, 221-232. [CrossRef]

38. Lee, J.-W.; Lee, E.-J. Regulation and function of the Salmonella MgtC virulence protein. J. Microbiol. 2015, 53, 667-672. [CrossRef]

39. Zou, W.; Al-Khaldi, S.F.; Branham, W.S.; Han, T.; Fuscoe, J.C.; Han, J.; Foley, S.L.; Xu, J.; Fang, H.; Cerniglia, C.E.; et al. Microarray analysis of virulence gene profiles in Salmonella serovars from food/food animal environment. J. Infect. Dev. Ctries. 2011, 5, 94-105. [CrossRef]

40. Bertelloni, F.; Tosi, G.; Massi, P.; Fiorentini, L.; Parigi, M.; Cerri, D.; Ebani, V.V. Some pathogenic characters of paratyphoid Salmonella enterica strains isolated from poultry. Asian Pac. J. Trop. Med. 2017, 10, 1161-1166. [CrossRef]

41. Fois, F.; Piras, F.; Torpdahl, M.; Mazza, R.; Consolati, S.G.; Spanu, C.; Scarano, C.; De Santis, E.P.L. Occurrence, characterization, and antimicrobial susceptibility of Salmonella enterica in slaughtered pigs in sardinia. J. Food Sci. 2017, 82, 969-976. [CrossRef]

42. Akiyama, T.; Presedo, J.; Khan, A.A. The tetA gene decreases tigecycline sensitivity of Salmonella enterica isolates. Int. J. Antimicrob. Agents 2013, 42, 133-140. [CrossRef]

43. Calayag, A.M.B.; Paclibare, P.A.P.; Santos, P.D.M.; Bautista, C.A.C.; Rivera, W.L. Molecular characterization and antimicrobial resistance of Salmonella enterica from swine slaughtered in two different types of Philippine abattoir. Food Microbiol. 2017, 65, 51-56. [CrossRef] [PubMed]

44. Maka, L.; Maćkiw, E.; Ściezyńska, H.; Modzelewska, M.; Popowska, M. Resistance to sulfonamides and dissemination of sul genes among salmonella spp. isolated from food in Poland. Foodborne Pathog. Dis. 2015, 12, 383-389. [CrossRef] [PubMed]

45. Antunes, P.; Machado, J.; Sousa, J.C.; Peixe, L. Dissemination of sulfonamide resistance genes (sul1, sul2, and sul3) in Portuguese Salmonella enterica strains and relation with integrons. Antimicrob. Agents Chemother. 2005, 49, 836-839. [CrossRef] [PubMed]

46. Wu, S.; Dalsgaard, A.; Hammerum, A.M.; Porsbo, L.J.; Jensen, L.B. Prevalence and characterization of plasmids carrying sulfonamide resistance genes among Escherichia coli from pigs, pig carcasses and human. Acta Vet. Scand. 2010, 52, 47. [CrossRef]

47. Pezzella, C.; Ricci, A.; DiGiannatale, E.; Luzzi, I.; Carattoli, A. Tetracycline and streptomycin resistance genes, transposons, and plasmids in Salmonella enterica isolates from animals in Italy. Antimicrob. Agents Chemother. 2004, 48, 903-908. [CrossRef] 
48. Dionisi, A.M.; Lucarelli, C.; Benedetti, I.; Owczarek, S.; Luzzi, I. Molecular characterisation of multidrug-resistant Salmonella enterica serotype infantis from humans, animals and the environment in Italy. Int. J. Antimicrob. Agents 2011, 38, 384-389. [CrossRef]

49. Argüello, H.; Guerra, B.; Rodríguez, I.; Rubio, P.; Carvajal, A. Characterization of antimicrobial resistance determinants and class 1 and class 2 integrons in salmonella enterica spp., multidrug-resistant isolates from pigs. Genes (Basel) 2018, 9, 256. [CrossRef]

50. Kaczorek-Łukowska, E.; Sowińska, P.; Franaszek, A.; Dziewulska, D.; Małaczewska, J.; Stenzel, T. Can domestic pigeon be a potential carrier of zoonotic Salmonella? Transbound. Emerg. Dis. 2020. [CrossRef]

Publisher's Note: MDPI stays neutral with regard to jurisdictional claims in published maps and institutional affiliations.

(C) 2020 by the authors. Licensee MDPI, Basel, Switzerland. This article is an open access article distributed under the terms and conditions of the Creative Commons Attribution (CC BY) license (http://creativecommons.org/licenses/by/4.0/). 